\title{
Correlation of academic adaptation and commitment to social activity in university students with chronic diseases
}

\author{
Rail Shamionov ${ }^{1,{ }^{*}, \text { Marina } \text { Grigoryeva }^{1} \text {, Elena Grinina }}{ }^{1}$, and Aleksey Sozonnik ${ }^{1}$ \\ ${ }^{1}$ Saratov State University, Center for support of families with children having special educational needs, \\ Astrakhanskaya St., 83, Saratov, Russia
}

\begin{abstract}
Adaptation of students with chronic diseases to the university educational environment is an important challenge in keeping with the equal opportunity strategy. This process is fraught not only with difficulties, but also with those opportunities that can be created within the framework of the versatile social activity of students. The aim of the research is to study the correlation between academic adaptation and adherence to various forms of social activities in students with chronic diseases and those without health limitations. The study involved 419 full-time students. We used an original questionnaire aimed at identifying socio-demographic characteristics, a methodology for assessing the components of academic adaptation and a scale of commitment to various forms of social activities. Our research revealed differences in adherence to the forms of social activities. We identified multiple linkages between academic adaptation and Internet cognitive, educational and socio-political forms of activities among students with chronic diseases, as well as linkages between leisure, civic, educational, protest, radical protest and subcultural forms of activities among students without chronic diseases. We found specificity in predicting academic adaptation in students' commitment to certain forms of social activities. We offer recommendations for psychological and pedagogical support of academic adaptation to students with chronic diseases.
\end{abstract}

\section{Introduction}

Inclusion in the educational space of the university, adaptation to educational conditions are significant factors in the successful learning of students, their mastery of professional competencies, inclusion in the society and socialization. The success of academic adaptation, in turn, may be due to the influence of a number of factors of personal, socio-psychological, organizational, methodological, etc. character. Understanding the mechanisms and factors of academic adaptation will make it possible to build an effective strategy for psychological and pedagogical support of education at the university, to take into account the individual and typological students' needs. Students with chronic diseases are a specific group, so far insufficiently studied, but becoming increasingly widespread. As a rule, they do not fall into the field of close attention of the psychological service of the university, unlike, for example,

\footnotetext{
*Corresponding author: shamionov@info.sgu.ru
} 
students with disabilities (special needs). However, while learning they can also face certain difficulties and obstacles that challenge their academic adaptation. From this perspective, the study of the characteristics and factors of academic adaptation in students with chronic diseases is of particular relevance.

The interest of psychological science in studies of the academic adaptation of students with Chronic Diseases is due to a number of reasons: first, an increase in their number [1]; secondly, chronic diseases of students have a different etiology, which does not allow developing unambiguous decisions on their social support and follow-up. Thirdly, for some of them the process of academic adaptation is ongoing constructively, while for others it is a great shock because of which they cannot get used to new requirements and their new status [2]. Fourth, the social challenges of the university educational environment, implying adherence to several forms of activity, determine the transformation of students' personal activity for their successful academic adaptation in particular and socialization in general [3]. Fifth, it has been proved that the academic adaptation of students with Chronic Diseases has some peculiarities compared to the academic adaptation of healthy students. This is manifested in low indicators of its psychophysiological, emotional-evaluative and personal regulatory components [4].

The difficulty of understanding and researching the academic adaptation of students with disabilities lies in the fact that for each specific group of students with chronic diseases there exist unique adaptation problems, and as a consequence, specific needs and support [5].

Academic adaptation today is understood as a multicomponent phenomenon, in whose structure different authors include various components: socio-psychological, psychological and activity oriented [6]; social, personal and academic [7]; pedagogical, psychophysiological, professional [8]; didactic, social and professional [9], as well as emotional, intellectual and socio-psychological [10]. Though the phenomenon of academic adaptation has recently become the subject of close attention of researchers, it is currently being studied quite intensively. Its various aspects are considered in a number of works [1117].

The formation of academic adaptation occurs under the influence of the cognitive characteristics of students [18], their school academic self-esteem [19], basic psychological needs, academic motivation and alienation from studies [20], health status [21], psychological and emotional well-being [22] and other factors. Their contribution to the structure and originality of academic adaptation is different and in all cases is refracted through the prism of the student's typological and individual characteristics.

Along with identifying general patterns of academic adaptation, it is important to study its specificity in various groups of students, in particular, in students with chronic diseases. The latter can go through academic adaptation in a peculiar way due to their psychophysiological characteristics. Thus, for people with chronic diseases, a decrease in endurance is characteristic, which has a global impact on both physical and cognitive functions [23], originality of the emotional sphere with the actualization of anxiety [24], selfesteem [25] and other features. On the other hand, it would be rash to believe that the development and adaptation opportunities of people with chronic diseases are definitely lower than those of conventionally healthy people. Thus, a dual effect of a chronic illness on the psyche is possible: on the one hand, the experience of stress is actualized, emotional maladjustment intensifies and affective reactions arise, on the other hand, the forces necessary to cope with the disease are mobilized [26]. Nevertheless, a number of works emphasize occurrence of difficulties in adapting to university studies among students with chronic diseases.

According to Soldatov et al. [27] chronic diseases are observed in 49\% of students, who are characterized by decreased performance and increased irritability $(88 \%)$, signs of vegetative dysfunction (from $20 \%$ to $43 \%$ ). Pronounced signs of psychosocial maladjustment 
are noted in $77 \%$ of students with chronic diseases [28]. Mullins et al. [29] note an increase in the level of anxiety, symptoms of depression, actualization of uncertainty and intrusiveness connected with the chronic disease. A study by Francis et al. [30] found that 27\% of firstyear students reported having chronic diseases. These students feel the need for academic support, the most problematic areas for them being formation of strategies for stress management and self-defense. These tendencies indicate the need for closer attention to the problem of academic adaptation of students with chronic diseases. Consideration of its features and formation factors will contribute to a more effective creation of equal conditions for education among such students.

Students' social activity may be viewed as a significant factor and indicator of their academic adaptation. A person's social activity is considered in the context of his socialization as its effect characterizing a person's ability to take actions in relation to social objects aimed at their change and transformation in accordance with his social essence, which result in a change in the subject, object and social situation in general [31].

Our research aims to study the forms of social activity that are the most important predictors of academic adaptation of students with and without chronic diseases. We assume that academic adaptation and certain forms of social activity are interrelated and there is specificity in predicting academic adaptation in students' commitment to certain forms of social activity.

The study involved 419 full-time university students from years 1-4 aged 17-26; average age $\mathrm{M}=19.6, \mathrm{SD}=2.8$ (men 18.4\%), including 32 (7.6\%) students with disabilities, 146 $(34.8 \%)$ students with chronic diseases.

The experimental studies were performed in accordance with the Ethical Standards (2000) and were approved by the local research Ethics Committee of the faculty of Psychological, Pedagogical, and Special Education, Saratov State University.

\section{Methods and techniques}

The authors developed and used a questionnaire to assess socio-demographic characteristics (gender, age, habitat, income level) and socialization conditions (for example, parenting styles). The scales of the Methodology for diagnosing the components of socially oriented activity were used to study the forms of students' social activity [32]. The following forms of students' social activity were studied: altruistic activity (AD); leisure activity (LA); sociopolitical activity (SPA); Internet Network Activity (INA); Internet searching activity (ISA); civic engagement (CE); socio-economic activity (SEA); educational and developmental activity (EDA); spiritual activity (SpA); religious activity (RA); protest activity (PA); radical protest activity (RPA); subcultural activity $(\mathrm{SA})(\alpha$ Cronbach $=0.68-0.70)$.

To assess the components of students' academic adaptation, the "Scale of Academic Adaptation" was used (Shamionov, Grigorieva, Grinina and Sozonnik). The techniques made it possible to identify the levels of academic adaptation according to the following structural indicators: personal (self-organization); emotionally evaluative; cognitive; motivational; psychophysiological; communicative components, and also to determine the integral assessment of academic adaptation ( $\alpha$ Cronbach $>0.93$ ).

Study design. First, we analyze the average indicators of students' academic adaptation in two groups. Then, the results of the correlation analysis of academic adaptation and commitment to forms of social activity are presented. Finally, the results of the regression analysis are presented. 


\section{Research results}

Let us turn to the data reflecting the arithmetic mean indicators of adherence to various forms of social activity among students without chronic diseases and students with chronic diseases.

Table 1. Forms of social activity of students with chronic diseases and those without chronic diseases (mean, standard deviations and coefficients of Student's test).

\begin{tabular}{|c|c|c|c|c|c|c|}
\hline \multirow{2}{*}{$\begin{array}{c}\text { Forms of } \\
\text { activity }\end{array}$} & \multicolumn{2}{|c|}{$\begin{array}{c}\text { With chronic } \\
\text { diseases N=273 }\end{array}$} & \multicolumn{2}{c|}{$\begin{array}{c}\text { Without chronic } \\
\text { diseases N=146 }\end{array}$} & \multicolumn{2}{c|}{ Student's t-tests } \\
\cline { 2 - 7 } & Mean & SD & Mean & SD & t & p \\
\hline AA & 2.71 & 1.08 & 2.42 & 1.06 & 2.59 & 0.01 \\
\hline LA & 4.16 & 0.84 & 3.96 & 0.93 & 2.19 & 0.03 \\
\hline SPA & 1.54 & 0.81 & 1.42 & 0.68 & 1.66 & 0.10 \\
\hline INA & 3.44 & 1.30 & 3.63 & 1.13 & -1.59 & 0.11 \\
\hline ISA & 4.21 & 0.95 & 4.37 & 0.82 & -1.77 & 0.08 \\
\hline CE & 1.99 & 1.07 & 1.84 & 0.95 & 1.50 & 0.13 \\
\hline SEA & 2.33 & 1.30 & 2.42 & 1.41 & -0.65 & 0.52 \\
\hline EDA & 2.80 & 1.11 & 2.76 & 1.13 & 0.37 & 0.72 \\
\hline SpA & 2.81 & 1.17 & 3.15 & 1.29 & -2.63 & 0.01 \\
\hline RA & 1.64 & 1.03 & 1.53 & 0.92 & 1.12 & 0.26 \\
\hline PA & 1.22 & 0.60 & 1.23 & 0.65 & -0.14 & 0.89 \\
\hline RPA & 1.26 & 0.69 & 1.16 & 0.63 & 1.54 & 0.13 \\
\hline SA & 1.36 & 0.79 & 1.25 & 0.70 & 1.45 & 0.15 \\
\hline
\end{tabular}

Table 1 shows that students with and without signs of chronic diseases differ but only a little in the forms of their activities. At the same time, the altruistic and leisure forms of activities are more pronounced in students without chronic diseases, while spiritual activity is more pronounced in students with chronic diseases.

Correlation analysis made it possible to establish that the relationship between the components of academic adaptation and commitment to various forms of social activity of healthy students is $37.2 \%$ of highly significant connections, and for students with chronic diseases it is only $17.9 \%$. Based on the results of the correlation analysis, one can state the presence of connections with the forms of activity that are "sensitive" for modern students" education. Thus, the analysis reveals relationships between academic adaptation and Internet cognitive $(r=0.172, p<0.05)$, educational $(r=0.327, p<0.01)$ and socio-political $(r=0.169$, $\mathrm{p}<0.05$ ) forms of activities in students with chronic diseases. At the same time, in healthy students the interrelation is as follows: with leisure $(\mathrm{r}=0.123, \mathrm{p}<0.05)$, civil $(\mathrm{r}=0.163, \mathrm{p}$ $<0.01)$, educational $(\mathrm{r}=0.246, \mathrm{p}<0.04)$, protest $(\mathrm{r}=0.138, \mathrm{p}<0.05)$, radical protest $(\mathrm{r}=$ $0.192, \mathrm{p}<0.01)$ and subcultural $(\mathrm{r}=0.195, \mathrm{p}<0.01)$ forms of activities.

Regression analysis performed by the step-by-step method allowed us to establish predictors of students' academic adaptation. As can be seen from Table 2, four forms of social activities of healthy students explain $16 \%$ of variations in academic adaptation and one form of activity explains $11 \%$ of variations in adaptation of students with chronic diseases. Educational activity is, in both cases, the leading predictor of academic activity. However, if among students with chronic diseases it is the only one in the regression equation, then among students without chronic disorders it also includes civic activity with a positive sign and radical protest and subcultural forms of activities with a negative one. 
Table 2. Results of Regression Analysis.

\begin{tabular}{|c|c|c|c|c|}
\hline Predictors & \multicolumn{1}{|c|}{ SR } & Beta & t \\
\hline \multicolumn{5}{|c|}{ Students without chronic diseases } \\
\hline EA & 0.06 & 0.249 & 3.999 & 0.01 \\
\hline RPA & 0.06 & -0.232 & -3.803 & 0.01 \\
\hline SA & 0.02 & -0.145 & -2.451 & 0.02 \\
\hline CE & 0.02 & 0.128 & 2.057 & 0.04 \\
\hline \multicolumn{5}{|c|}{ Students with chronic diseases } \\
\hline \multicolumn{5}{|c|}{$\mathrm{R}^{2}=0.16 ; \mathrm{F}=12.29, \mathrm{p}<0.01$} \\
\hline EA & $0.11 \quad \mathrm{R}^{2}=0.11 ; \mathrm{F}=17.19, \mathrm{p}<0.01$ \\
\hline
\end{tabular}

\section{Discussion of the results}

The academic adaptation of students with chronic diseases is fundamentally important for their education and health preservation. Obviously, one of the significant factors of adaptation is the activities they are involved in various spheres of student life. Our study aims to reveal this part of the predicted academic adaptation of students.

The significance of some forms of social activity is different for students with and without chronic diseases (see Table 1). Altruistic and leisure activities are more important for students without chronic diseases. Obviously, students without chronic diseases are more motivated and ready to realize themselves in these two forms of activities than students with chronic diseases, since the latter have limitations in the internal reserves of the body due to focusing on overcoming their own problem. Therefore, the problems of other people and the altruistic activity to help them are not relevant for students with chronic diseases.

Leisure activities associated with positive experiences for students with chronic diseases may not be consistent with their well-being and affective background, therefore it is also not as significant as for their healthy peers. This fact agrees with the results obtained by Odintsova, Aismontas and Kulyatskaya [33]. Researchers, when comparing students with chronic diseases and without chronic diseases, found that healthy students consider themselves more successful, having more opportunities and more clearly envisioning their future. In addition, the authors emphasize that students with disabilities more often think about their disease, believe that the disease prevents them from living the way they would like, ... more often they experience painful conditions and consider their life less fulfilling [33].

Spiritual activity, on the contrary, is significantly more important for students with chronic diseases. Presumably, turning to spiritual practices, students with chronic diseases strengthen their resilience and seek to compensate for the physical limitations associated with the disease.

The correlation analysis revealed that the academic adaptation of students without chronic diseases is to a greater extent interconnected with various forms of social activities (see the section Results). This indicates a greater role of social activities in achieving the result of academic adaptation among students without chronic diseases. The social activity of healthy students in various fields, even not related to education, contributes to a positive result of academic adaptation. Allegedly, students without chronic diseases, having the strength and ability to express themselves in various fields, acquire adaptation skills and communicative competence, which helps them adapt to the educational environment. Students with chronic 
diseases are often limited in space and their physical capabilities, so they are less active in various areas. Chernobrovkina and Grushko [34] also write about this, noting that in healthy students, socio-psychological adaptation depends on various aspects of the student's personality and activities, and students with chronic diseases strive to streamline their lives and try to apply a limited number of proven adaptation actions.

A predictor of academic adaptation of students with chronic diseases is social activity only in the field of education (Table 2). By limiting the spheres of their activity, students with chronic diseases may have limitations in acquiring communicative competence and adaptation skills. Melekhova and Vyazova [35] also note the low capability for activity and initiative of students with disabilities. The authors refer to low self-motivation, insufficiently developed self-regulation, negative cognitive attitudes, and low social competence as reasonsIbid. Educational and civic activities are positive predictors of academic adaptation in students without chronic diseases. Obviously, civic engagement enhances the activity in the field of education and, consequently, academic adaptation due to the awareness of their role in society and the ability to fulfill it. It is also possible that students with chronic diseases do not clearly conceive their present and future role in society.

Radical protest and subcultural activity are the negative predictors of academic adaptation of students without chronic diseases (Table 2). It should be noted that when calculating individual paired correlations of academic adaptation and forms of social activity, positive correlation coefficients were obtained between these indicators. This can be explained by the positive contribution of certain forms of social activity to academic adaptation, but with the simultaneous social activity of students without chronic diseases in several areas of social interactions, the types of social activity are differentiated in the direction of influence: educational and civic have a positive effect on academic adaptation, and radical protest and subcultural a negative one.

\section{Conclusions}

Altruistic and leisure forms of activity are of less importance for students with chronic diseases due to the concentration of their attention on their own problems and negative affective background, extrinsic to leisure activity.

Spiritual activity for students with chronic diseases is of greater importance due to its potential to increase vitality and neuro-psychic stability.

For students without chronic diseases, civic engagement enhances activities in the field of education resulting in academic adaptation due to the awareness of their role in society and the possibilities for its implementation.

Certain forms of social activity make a positive contribution to the academic adaptation of students without chronic diseases, but with the simultaneous social activity of healthy students in several areas of social interactions, the types of social activity are differentiated in the direction of influence: educational and civic positively affect academic adaptation, while radical protest and subcultural activity produce a negative effect.

\section{Limitation}

The study shows that among students with chronic diseases the forms of social activity aimed at the academic adaptation are narrowed to educational activity only, which is its main predictor. In contrast to them, among students who do not have chronic diseases, academic adaptation is associated with a number of forms of activity, including the rejection of radical protest and subcultural activity. These data indicate the need to create such opportunities for students with chronic diseases that would facilitate their communication and fill up their 
social life with meaningful forms of activities. It is also important to mark out the need for a deeper analysis of the compensatory activity of students with chronic diseases. This will build up a better educational environment adapted to the needs and capabilities of these students, as well as foster the integration of the entire student community, ensuring equal opportunities for everyone.

\section{Funding}

This research was funded by the Ministry of Science and Higher Education of the Russian Federation within the framework of the project "Socio-psychological, psychological and psycho-physiological factors, characteristics and mechanisms of academic adaptation in students with special educational needs", grant number FSRR-2020-0003.

\section{Acknowledgments}

The authors express their gratitude to the Center for support of families with children having special educational needs for organizational and technical assistance in the study.

\section{References}

1. L. Kendall, Higher education and disability: Exploring student experiences. Cogent Education 3(1) (2016) https://doi.org/10.1080 / 2331186X.2016.1256142

2. W. Arscott, Students with Learning and Developmental Disabilities in Post Secondary Education (2013) https://doi.org/10.1007/978-94-6209-046-0_9

3. R.M. Shamionov, SHS Web of Conferences 70, 08037 (2019) https://doi.org/10.1051 / SHS conf / 20197008037

4. R.M. Shamionov, M.V. Grigoryeva, E.S. Grinina, A.V. Sozonnik, Eur. J. Investig. Health. Psychol. Educ 10, 816-831 (2020) https://doi.org/10.3390 / ejihpe10030059

5. O. Lipka, M. Sarid, I. Aharoni Zorach, A. Bufman, A.A. Hagag, H. Peretz, Adjustment to Higher Education: A Comparison of Students With and Without Disabilities. Front. Psychol. (2020) https://doi.org/10.3389/fpsyg.2020.00923

6. V.V. Lagerev, Adaptation of students to the conditions of training in a technical university and the peculiarities of the organization of the educational process with freshmen (NIIVO, Moscow, 1991)

7. T.V. Dorozhevets, Diagnostics of school maladjustment (Vit.univ.press, Vitebsk, 1995)

8. V.I. Kovalev, V.N. Druzhinin, Psychological journal 3(6), 33-44 (1982)

9. A.A. Smirnov, N.G. Zhivaev, Psychology of university adaptation: textbook (YarsSU, Yaroslavl, 2009).

10. M.V. Grigorieva, School adaptation: mechanisms and factors in different learning conditions (Sarat. univ.press, Saratov, 2008)

11. A.V. Karpov, V.E. Orel, V.Ya. Ternopol, Psychology of professional adaptation (Avers Press, Yaroslavl, 2003)

12. G.V. Bezyuleva, Psychological and pedagogical support of professional adaptation of pupils and students: monograph (NOU VPO Moscow Psychological and Social Institute, Moscow, 2008)

13. R.M. Shamionov, Psychology of education 9, 20-30 (2013) 
14. M.V. Grigorieva, R.M. Shamionov, N.M. Golubeva, Psychological Science and Education 22(5), 23-30 (2017) https://doi.org/10.17759 / pse.2017220503

15. J.I. Bisson, D. Sakhuja, Psychiatry 5(7), 240-242 (2006) https://doi.org/10.1053/j.mppsy.2006.04.004

16. T. Abry, C.I. Bryce, J. Swanson, R. Bradley, R. Fabes, R.F. Corwyn, Developmental psychology 53(3), 497-510 (2017) https://doi.org/10.1037/dev0000268

17. P. Lakhani, K. Jain, P. Chandel, International Journal of Management and Social Sciences 7(10), 333-348 (2017)

18. N.J. Mackintosh, IQ and Human Intelligence (Oxford, N.Y., 2006)

19. S. Wouters, V. Germeijs, H. Colpin, K. Verschueren, Scandinavian journal of psychology 52(6), 568-594 (2011) https://doi.org/10.1111/j.1467-9450.2011.00905.x

20. V.N. Pulyaeva, A.N. Nevryuev, Psychological Science and Education 25(2), 19-32 (2020) https://doi.org/10.17759/ pse.2020250202

21. I.S. Zimina, M.N. Gavrilova, O.V. Polozova, S.A. Mukhina, Bulletin of the Orenburg State University 6(194), 3-8 (2016)

22. M.V. Buchatskaya, M.V. Kapranova, Psychological Science and Education 20(2), $63-$ 69 (2015) https://doi.org/10.17759 / pse.2015200207

23. C. Hale, Reclaiming 'Chronic Illness' (Center for Welfare Reform, 2018)

24. A.E. Green, J. Ferrand, G.A. Aarons, Journal of Developmental \& Behavioral Pediatrics 37(8), 637-646 (2016) https://doi.org/10.1097/DBP.0000000000000336

25. D.S. Kornienko, A.I. Kozlov, M.L. Otavina, Hygiene and Sanitation 95(6), 577-581 (2016) https://doi.org/10.18821/0016-9900-2016-95-6-577-581

26. A.A. Lifintseva, T.D. Derkach, N. Shtolde, Clinical and special psychology 7(1), 1-12 (2018) https://doi.org/10.17759 / cpse.2018070101

27. A.A. Soldatov, O.E. Kovtun, N.G. Radzievskaya, et al, International Journal on Immuno-rehabilitation 12(2), 241 (2010)

28. P.I. Sidorov, A.G. Soloviev, I.A. Novikova, Hygiene and sanitation 4, 46-49 (2001)

29. A.J. Mullins, K.L. Gamwell, C.M. Sharkey, et al, Journal of American College Health 65(5), 352-360 (2017) https://doi.org/10.1080/07448481.2017.1312415

30. G.L. Francis, J. Duke, F.J. Brigham, K. Demetro, Journal of Autism and Developmental Disorders 48, 3573-3585 (2018) https://doi.org/10.1007 / s10803-018-3622-x

31. R.M. Shamionov, RUDN Journal of Psychology and Pedagogics 15(4), 379-394 (2018) https://doi.org/10.22363 / 2313-1683-2018-15-4-379-394

32. R.M. Shamionov, M.V. Grigorieva, Siberian psychological journal 74, 26-41 (2019) https://doi.org/10.17223 / 17267080/74/2

33. M.A. Odintsova, B.B. Aismontas, M.G. Kulyatskaya, Izv. SSU. New ser. Ser. Philosophy. Psychology. Pedagogy 17(1), 72-79 (2017) https://doi.org/10.18500 / 18197671-2017-17-1-72-79

34. S.V. Chernobrovkina, N.V. Grushko, Bulletin of Omsk University. Series: Psychology 3, 39-51 (2017)

35. V.M. Melekhova, N.V. Vyazova, Humanities 2(42), 90-100 (2018) 